\section{(1) \\ CrossMark}

\title{
Ceramide-1-phosphate inhibits cigarette smoke-induced airway inflammation
}

\author{
Kristin Baudi ${ }^{1}$, Cemil Korcan Ayata ${ }^{1}, Z^{2}$ sofia Lazar ${ }^{1}$, Sanja Cicko ${ }^{1}$, \\ Jessica Beckert ${ }^{1}$, Anja Meyer ${ }^{1}$, Andreas Zech ${ }^{1}$, Rodolfo Paula Vieira ${ }^{1}$, \\ Robert Bittman², Antonio Gómez-Muñoz ${ }^{3}$, Irmgard Merfort ${ }^{4}$ and Marco Idzko
}

Affiliations: ${ }^{1}$ Dept of Pneumology, COPD and Asthma Research Group, University Hospital Freiburg, Freiburg, Germany. ${ }^{2}$ Dept of Chemistry and Biochemistry, Queens College, City University of New York, Flushing, NY, USA. ${ }^{3}$ Dept of Biochemistry and Molecular Biology, University of the Basque Country, Bilbao, Spain. ${ }^{4}$ Dept of Pharmaceutical Biology and Biotechnology, Institute of Pharmaceutical Sciences, University of Freiburg, Freiburg, Germany.

Correspondence: Marco Idzko, Dept of Pneumology, COPD and Asthma Research Group (CARG), University Hospital Freiburg, Killianstrasse 5, 79106 Freiburg, Germany. E-mail: marco.idzkoduniklinik-freiburg.de

ABSTRACT Sphingolipids are involved in the pathogenesis of inflammatory diseases. The central molecule is ceramide, which can be converted into ceramide-1-phosphate (C1P). Although C1P can exert anti- and pro-inflammatory effects, its influence on cigarette smoke (CS)-induced lung inflammation is unknown. We aimed to clarify the role of C1P in the pathogenesis of CS-triggered pulmonary inflammation and emphysema in humans and mice.

The effects of C1P were addressed on CS-induced lung inflammation in C57BL/6 mice, CS extracttriggered activation of human airway epithelial cells (AECs) and neutrophils from patients with chronic obstructive pulmonary disease. Differential cell counts in bronchoalveolar lavage fluid were determined by flow cytometry and pro-inflammatory cytokines were measured by ELISA. Expression and DNA binding of nuclear factor (NF)- $\kappa \mathrm{B}$ and neutral sphingomyelinase (nSMase) were quantified by PCR, electrophoretic mobility shift and fluorometric assays.

C1P reduced CS-induced acute and chronic lung inflammation and development of emphysema in mice, which was associated with a reduction in nSMase and NF- $\mathrm{BB}$ activity in the lungs. nSMase activity in human serum correlated negatively with forced expiratory volume in $1 \mathrm{~s} \%$ predicted. In human AECs and neutrophils, C1P inhibited CS-induced activation of NF- $\kappa \mathrm{B}$ and nSMase, and reduced pro-inflammatory cytokine release.

Our results suggest that $\mathrm{C} 1 \mathrm{P}$ is a potential target for anti-inflammatory treatment in CS-induced lung inflammation.

@ERSpublications

Ceramide-1-phosphate, a potential target for anti-inflammatory treatment in cigarette smokeinduced lung inflammation http://ow.ly/E7tUS

This article has supplementary material available from erj.ersjournals.com

Received: April 302014 | Accepted after revision: Nov 62014 | First published online: Jan 222015

Support statement: This study was funded by the Deutsche Forschungsgemeinschaft DFG (grant ID 7/8-1). Z. Lazar was a recipient of the European Respiratory Society Long-term Research Fellowship (grant ID 50-2012). Funding information for this article has been deposited with FundRef.

Conflict of interest: None declared.

Copyright CERS 2015 


\section{Introduction}

Chronic obstructive pulmonary disease (COPD) is the third most common cause of death in the western community. Airflow limitation and chronic inflammatory response in the airways and the lungs are triggered by the inhalation of noxious particles or gases, commonly cigarette smoke (CS) [1]. This inflammation is characterised by the accumulation of macrophages and neutrophils in the lungs. Oxidative stress in the airways is an essential component of disease pathogenesis. It activates the transcription factor nuclear factor $(\mathrm{NF})-\kappa \mathrm{B}$ in inflammatory and structural cells, inducing the production of pro-inflammatory cytokines and chemokines, such as tumour necrosis factor (TNF)- $\alpha$, interleukin (IL)-1 $\beta$ and IL-8 [2]. The chronic inflammatory cascade leads to alveolar wall destruction and the development of emphysema [3, 4].

Recent reports suggest that sphingolipids play a role in the pathogenesis of airway inflammation $[5,6]$. The central molecule ceramide triggers apoptosis of pulmonary epithelial cells, and increased pulmonary levels of ceramide lead to the development of emphysema in mice [5,7]. Furthermore, elegant in vitro and in vivo experiments emphasise that ceramide and its derivatives modulate chronic pulmonary inflammation in bronchial asthma $[8,9]$ and cystic fibrosis [6]. Ceramide is de novo generated by serine palmitoyl transferase, ceramide synthase or via membrane sphingomyelin hydrolysis by sphingomyelinase (SMase). It can be directly phosphorylated by ceramide kinase to ceramide-1-phosphate (C1P) [10]. Exogenous C1P prevents ceramide generation and inhibits the apoptotic effect of ceramide in alveolar macrophages [11, 12] and may block the neutral (n)SMase2-dependent apoptosis of human airway epithelial cells (AECs) [13]. Furthermore, phospho-ceramide analogue-1, an analogue of C1P, inhibits TNF- $\alpha$ release in RAW264.7 mouse macrophages [14]. However, a detailed study unravelling the role of $\mathrm{C} 1 \mathrm{P}$ in CS-induced lung inflammation in mice and humans is still missing.

The aim of this study was to investigate the effects of natural and synthetic C1P products on murine models of CS-induced emphysema, inflammatory response of human AECs and blood neutrophils from COPD patients. The underlying working mechanisms of $\mathrm{C} 1 \mathrm{P}$ were explored by measuring DNA binding and mRNA expression of NF- $\kappa \mathrm{B}$ and by assessing nSMase activity.

\section{Materials and methods}

A detailed description of the materials and methods can be found in the supplementary material.

\section{Reagents}

C8-C1P was purchased from Cayman Chemical (Ann Arbor, MI, USA) and aliquoted in ethanol. C16-C1P was acquired from Matreya LLC (Pleasant Gap, PA, USA) and solubilised in sterile nanopure water on ice using a probe sonicator as previously described [15]. Fresh lipopolysaccharide (LPS)-free cigarette smoke extract (CSE) was generated by bubbling smoke from one commercial cigarette (Marlboro; Philip Morris GmbH, Munich, Germany) at a constant rate through $10 \mathrm{~mL}$ RPMI with $0.1 \%$ fetal calf serum and penicillin/streptomycin. One burned cigarette is equivalent to $100 \%$ of CSE medium.

\section{Mice}

C57BL/6 mice (6-8 weeks old) were bred at animal facilities of the University Hospital Freiburg (Freiburg, Germany). All experiments were approved by the animal ethics committee of the German government.

Mouse models of acute and chronic CS-induced lung inflammation

CS-induced lung inflammation was induced as previously described [16, 17]. C1P was administered as either intratracheal or oral instillations.

\section{Histological analysis of lungs}

Formalin-fixed, paraffin-embedded lung sections were stained with haematoxylin and eosin. Mean linear intercept (Lm) and internal surface area of the lung (ISA) were calculated as previously described [17].

\section{Cell culture experiments}

Human bronchial BEAS-2B and alveolar A549 epithelial cells were cultured as previously described [18]. $5 \times 10^{5}$ cells.well $^{-1}$ were seeded in a six-well plate and pre-treated with C1P prior to CSE stimulation. $6 \mathrm{~h}$ later, supernatants were collected for cytokine measurement. To measure NF- $\kappa \mathrm{B}$ activation, cells were stimulated with 5\% CSE for $10 \mathrm{~min}$.

\section{Isolation and in vitro stimulation of human neutrophils}

Neutrophils were isolated using Pancoll gradient (PAN-Biotech GmbH, Aidenbach, Germany), as described previously [5], from 29 stable COPD patients (Global Initiative for Chronic Obstructive Lung Disease (GOLD) stages I, II, III and IV: $n=6, n=8, n=6$ and $n=9$, respectively), eight healthy ex-smokers and 15 healthy nonsmokers at the Dept of Pulmonology, University Hospital Freiburg. This study was 
approved by the local ethics committee and all participants gave written informed consent (subject characteristics are shown in the supplementary material). The purity of neutrophils was $>98 \%$ as assessed on cytospin slides. Cells were seeded into 24 -well plates $\left(1 \times 10^{6}\right.$ cells $\cdot$ well $\left.^{-1}\right)$ in RPMI1640 culture medium and treated with C1P or vehicle for $1 \mathrm{~h}$ prior to $5 \%$ CSE for $18 \mathrm{~h}$. Supernatants were collected for cytokine measurements.

\section{Sphingomyelinase fluorometric assay}

nSMase activity was measured in murine lung tissue and in human sera with the SMase fluorometric assay kit (Cayman Chemical).

Other molecular and cellular analyses

Detailed information can be found in the supplementary material.

\section{Statistical analysis}

Groups were compared using one-way ANOVA followed by the Bonferroni post hoc test; correlation was analysed with Pearson correlations (GraphPad Prism, San Diego, CA, USA). A p-value $<0.05$ was considered significant.

\section{Results}

Exogenous C1P inhibits CS-induced lung inflammation

Similar to previous findings, mice exposed to the smoke of five cigarettes per day for 3 consecutive days displayed higher numbers of leukocytes (neutrophils and macrophages) (fig. 1a), higher total number of cells (mean \pm SD 113400 \pm 16486 ) and increased levels of pro-inflammatory cytokines in bronchoalveolar lavage fluid (BALF) (fig. $1 \mathrm{~b}$ and c) compared to air-exposed controls with a total mean $\pm \mathrm{SD}$ of cells in BALF of $33000 \pm 10816$. Intrapulmonary application of C8-C1P $\left(2.0 \mu \mathrm{g} \cdot \mathrm{kg}^{-1}\right)$ or C16-C1P $\left(1.6 \mu \mathrm{g} \cdot \mathrm{kg}^{-1}\right)$ 30 min prior to CS exposure attenuated inflammation as shown by a decrease in BALF leucocytosis and total BALF cell number (smoke/C16-C1P: mean \pm SD $44400 \pm 16211$; smoke/C8-C1P: mean \pm SD $50400 \pm 14$ 449), and a fall in concentrations of BALF cytokines, notably IL-1 $\beta$, IL-6, keratinocyte chemoattractant (KC) and macrophage inflammatory protein (MIP)-2. Moreover, leukocyte infiltration in the tissue was also reduced (fig. $1 \mathrm{~d}-\mathrm{g}$ ).
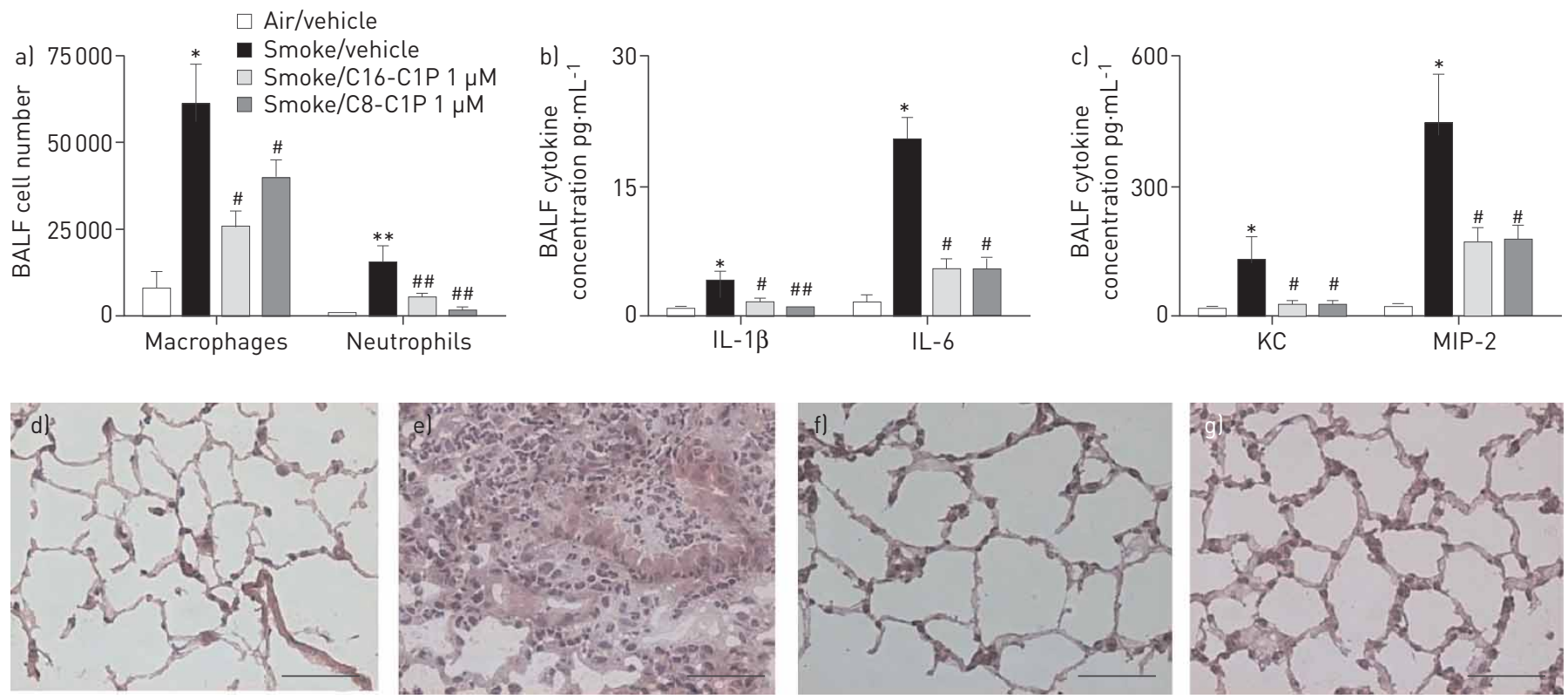

FIGURE 1 Administration of ceramide-1-phosphate (C1P) prior to cigarette smoke (CS) inhalation in a 3-day acute mouse model reduces airway inflammation. Prior to each CS challenge, C57BL/6 mice were treated intratracheally for 3 days with C1P $(1 \mu \mathrm{M})$ or vehicle. Directly after the last CS challenge animals were sacrificed. a) Bronchoalveolar lavage fluid (BALF) differential cell count was measured by flow cytometry. Concentrations of b) interleukin (IL)-1 $\beta$ and IL-6, and c) keratinocyte chemoattractant (KC) and macrophage inflammatory protein (MIP)-2 were determined in BALF by ELISA. d-g) Representative images of haematoxylin eosin-stained lung sections for d) air/vehicle, e) smoke/vehicle, f) smoke/C16-C1P $1 \mu \mathrm{M}$ and g) smoke/C8-C1P $1 \mu \mathrm{M}$. Data are presented as mean \pm SEM. $n=4-5$ mice in each group. One representative experiment out of three is shown. ${ }^{*}: \mathrm{p}<0.05,{ }^{* *}: \mathrm{p}<0.01$ smoke/vehicle versus air/vehicle; ${ }^{*}: \mathrm{p}<0.05$, \#\#: $\mathrm{p}<0.01$ smoke/C1P versus smoke/vehicle. Scale bars $=50 \mu \mathrm{m}$. 
Of note, the effect of C1P analogues was maintained, even when applied after the induction of CS-induced lung inflammation (starting at the fourth session of CS exposure) (supplementary material). We observed lower levels of CS-induced total BALF leukocytes (data not shown), neutrophils and macrophages (fig. 2a and c) when mice were administered with C1P before and after CSE exposure over a period of 3 days, suggesting that exogenous $\mathrm{C} 1 \mathrm{P}$ can prevent and also treat early stages of established CS-induced lung inflammation (fig. 2a-d).

\section{C1P partially prevents development of emphysema in a chronic model of CS-induced lung inflammation}

Next, to study the involvement of $\mathrm{C} 1 \mathrm{P}$ in the pathogenesis of emphysema, a mouse model of chronic CS-induced lung inflammation (characterised by the development of pulmonary emphysema) was used. Since repeated anaesthesia (3 days per week for 3 months) for intratracheal treatment would have been fatal for many animals, oral treatment with C8-C1P $\left(40 \mu \mathrm{g} \cdot \mathrm{kg}^{-1}\right)$ or C16-C1P $\left(50 \mu \mathrm{g} \cdot \mathrm{kg}^{-1}\right)$ was used. Prior to this, the relative potency of intratracheal versus oral treatment in the acute model of CS-induced lung inflammation was established. Accordingly, the oral dose of the drug with a comparable reduction in airway inflammation was more than 20 -fold higher by intratracheal administration (data not shown). As shown in figure 3, animals exposed to CS for 7 months demonstrated foci of emphysema disseminated throughout the lung parenchyma (fig. 3b) compared to air-exposed mice (fig. 3a). Oral treatment for the last 3 months with $\mathrm{C} 16-\mathrm{C} 1 \mathrm{P}$ and $\mathrm{C} 8-\mathrm{C} 1 \mathrm{P}$ (fig. $3 \mathrm{c}$ and $\mathrm{d}$ ) significantly reduced the signs of lung emphysema. The precise morphometric assessment of lung emphysema was performed as previously described [17], and the results are given in table 1.

After 7 months of smoke exposure, the average interalveolar distance (Lm) was significantly increased and the ISA was considerably decreased compared to the respective air-exposed group. The reduction of CS-induced lung emphysema and inflammation following C1P treatment was accompanied by a reduced number of total BALF leukocytes, as well as BALF macrophages and neutrophils (fig. 3e), and reduced cytokine levels of IL-1 $\beta$, IL-6, MIP-2 and KC (fig. $3 \mathrm{f}$ and g). Furthermore, the mRNA expression level of
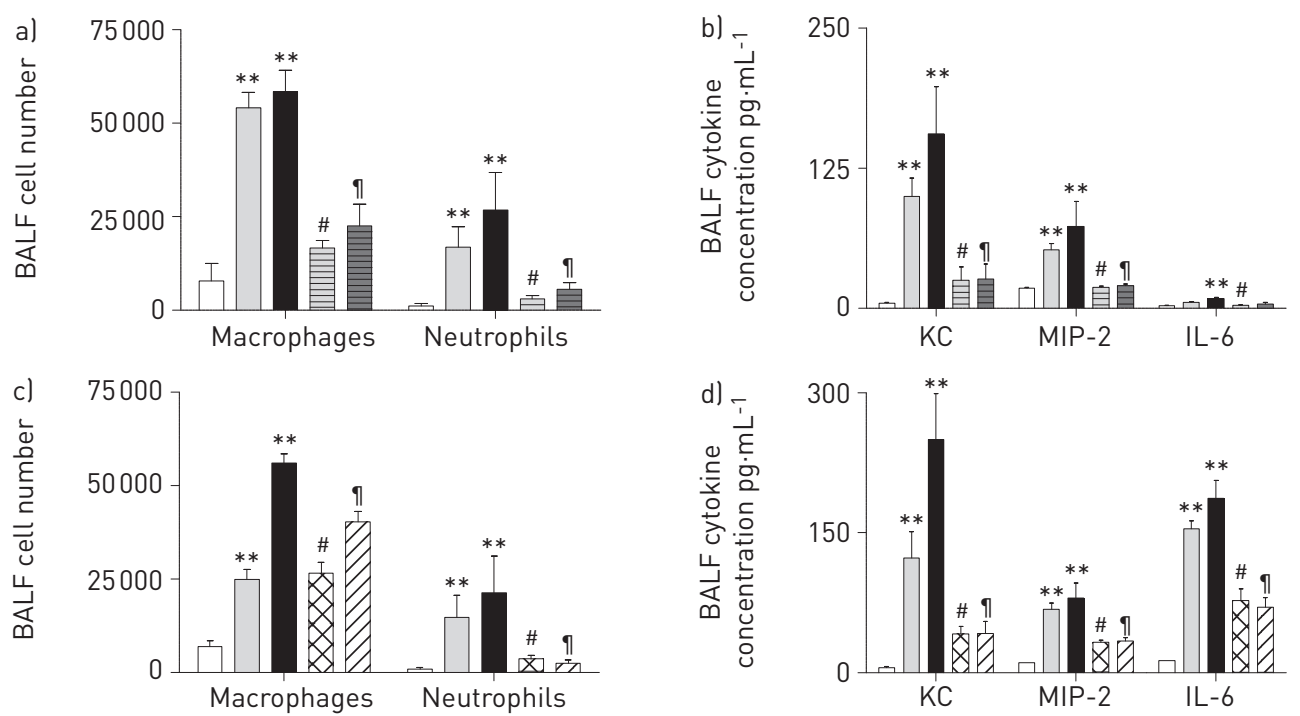

$\square$ Air 1-3 days/air+vehicle 4-6 days

$\square$ Smoke 1-3 days/air+vehicle 4-6 days

- Smoke 1-3 days/smoke+vehicle 4-6 days

$\boxminus$ Smoke 1-3 days/air+C16-C1P $1 \mu \mathrm{M} 4-6$ days

Smoke 1-3 days/smoke+C16-C1P $1 \mu \mathrm{M}$ 4-6 days

$\triangle$ Smoke 1-3 days/air+C8-C1P $1 \mu \mathrm{M}$ 4-6 days Smoke 1-3 days/smoke+C8-C1P $1 \mu \mathrm{M}$ 4-6 days

FIGURE 2 Anti-inflammatory effect of ceramide-1-phosphate (C1P) in ongoing cigarette smoke (CS)-induced lung inflammation. Mice received CS either for 6 or 3 consecutive days with an additional 3 days of exposure to room air. At days 4 to 6 , vehicle or a, b) C16-C1P $1 \mu \mathrm{M}$ or c, d) C8-C1P $1 \mu \mathrm{M}$ was instilled intratracheally 30 min prior to CS or air exposure. Mice were sacrificed $1 \mathrm{~h}$ after the last CS challenge. a, c) Bronchoalveolar lavage fluid (BALF) differential cell count was measured by flow cytometry. b, d) Keratinocyte chemoattractant (KC), macrophage inflammatory protein (MIP)-2 and interleukin (IL)-6 amounts were determined in BALF by ELISA. Data are presented as mean \pm SEM. $n=4-5$ mice in each group. One representative experiment out of three is shown. ${ }^{*}: \mathrm{p}<0.05$ smoke for $1-3$ days/air+C1P for 4-6 days versus smoke for 1-3 days/air+vehicle for 4-6 days; ๆ: $\mathrm{p}<0.05$ smoke for 1-3 days/smoke+C1P for 4-6 days versus smoke for 1-3 days/smoke+vehicle for 4-6 days; ${ }^{* *}: \mathrm{p}<0.01$ smoke for $1-3$ days/smoke or air+vehicle for $4-6$ days versus air for 1-3 days/air+vehicle for 4-6 days. 

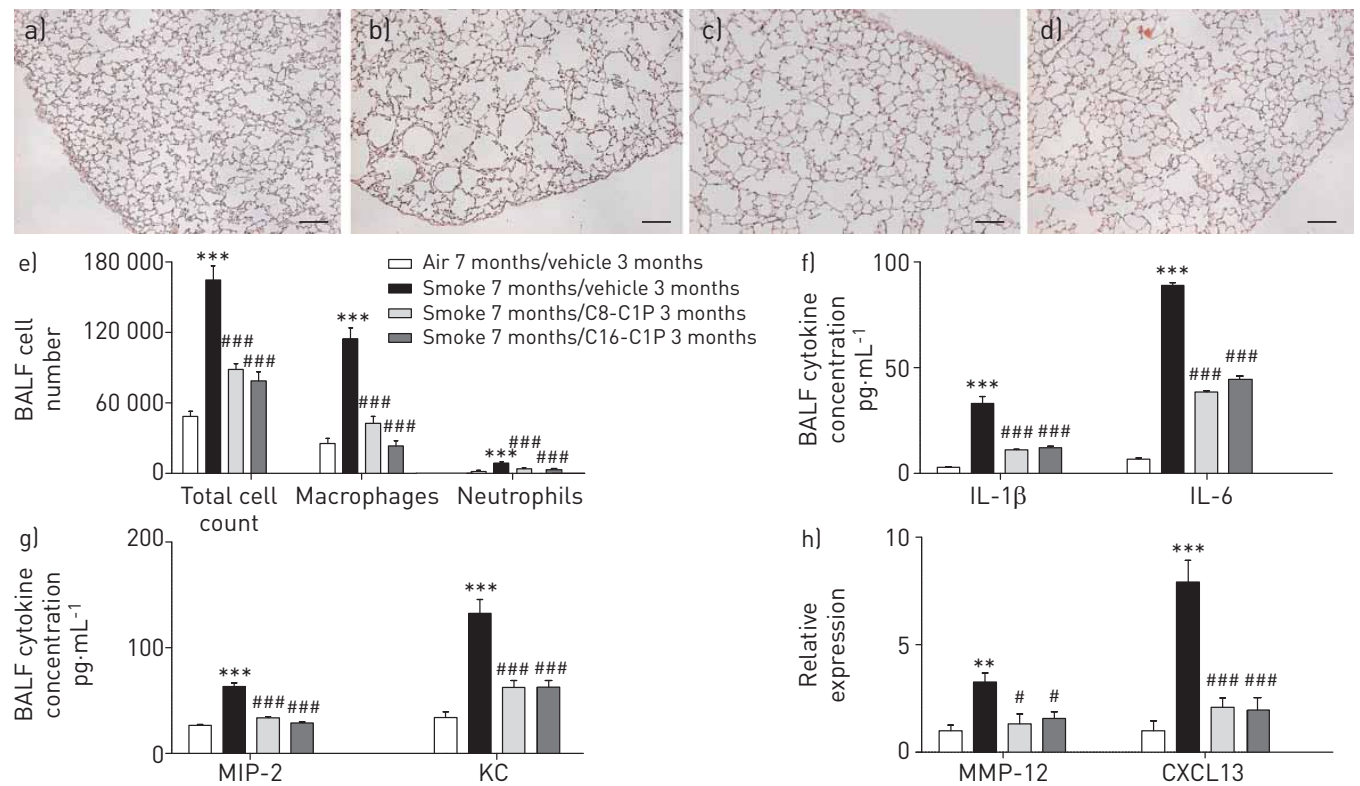

i)

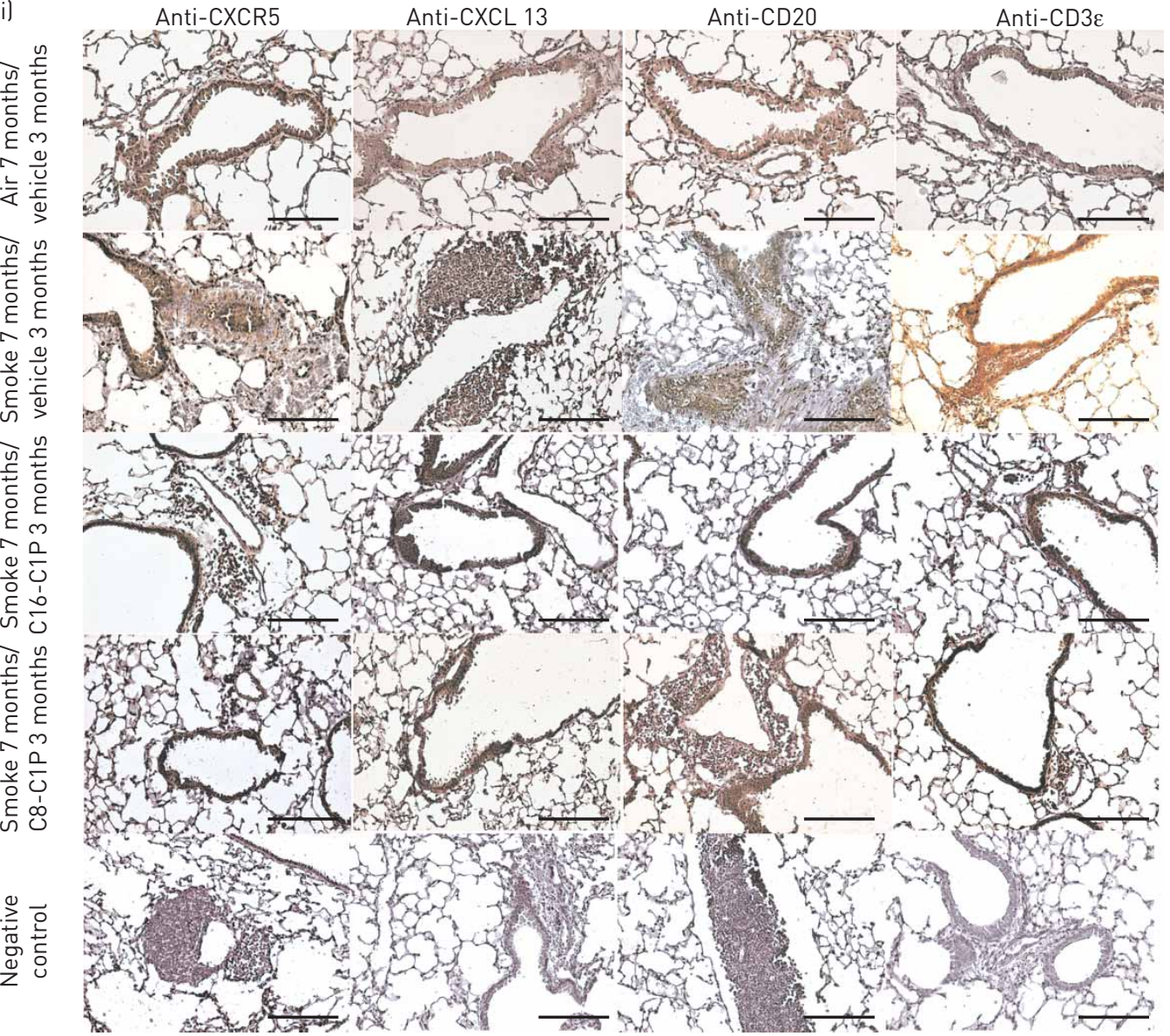

FIGURE 3 Ceramide-1-phosphate (C1P) reduces the development of emphysema in a mouse model of chronic cigarette smoke (CS)-induced lung inflammation. C57BL/6 mice were exposed to CS for 7 months and received C1P $(10 \mu \mathrm{M})$ or vehicle orally for the last 3 months. Lungs were isolated 1 day after the last smoke challenge and fixed under $20 \mathrm{~cm}$ formalin column for 2 days before being processed for histological emphysema analysis. a-d) Representative histological slides for a) air 7 months/vehicle 3 months, b) CS 7 months/vehicle 3 months, c) CS 7 months/C16-C1P 3 months and d) CS 7 months/C8-C1P 3 months. e) Bronchoalveolar lavage fluid (BALF) differential cell count, f) interleukin (IL)- $1 \beta$ and IL-6, and g) macrophage inflammatory protein (MIP)-2 and keratinocyte chemoattractant (KC). $\mathrm{n}=8-10$ mice in each group. h) Quantified PCR analysis of matrix metalloproteinase (MMP)-12 and CXCL13 mRNA expression in 7 months chronic CS mice model. $\mathrm{n}=5-7$ mice in each group. i) Representative images of immunohistochemistry staining of formalin-fixed, paraffin-embedded lung lobes for rabbit anti-mouse CXCR5, goat anti-mouse CXCL13, rabbit anti-mouse CD20, biotin armenian hamster anti-mouse CD3e antibody. No staining was detected using secondary antibody alone as negative control. Data are presented as mean \pm SEM. ${ }^{* *}: \mathrm{p}<0.01$, ${ }^{* * *}$ : $\mathrm{p}<0.001$ CS 7 months/vehicle 3 months versus air 7 months/vehicle 3 months; ${ }^{\#}: \mathrm{p}<0.05,{ }^{\# \# \#: ~} \mathrm{p}<0.001$ CS 7 months/C1P 3 months versus CS 7 months/vehicle 3 months. Scale bars=100 $\mu$ m. 
TABLE 1 Morphometric assessment of the effects of ceramide-1-phosphate (C1P) on the progression of emphysematous changes caused by cigarette smoke (CS) exposure

\begin{tabular}{|c|c|c|c|c|}
\hline \multirow[t]{2}{*}{ Groups } & \multicolumn{2}{|c|}{ Exposure/treatment } & \multicolumn{2}{|c|}{ Results at 7 months } \\
\hline & $0-4$ months & 5-7 months & $\operatorname{Lm} \mu \mathrm{m}$ & ISA $\mathrm{cm}^{2}$ \\
\hline A & Air/- & Air/vehicle & $20.6 \pm 0.8$ & $748 \pm 65$ \\
\hline B & $\mathrm{CS} /-$ & CS/vehicle & $32.3 \pm 3.2 *$ & $492 \pm 70 *$ \\
\hline C & CS/- & $\mathrm{CS} / \mathrm{C} 16-\mathrm{C} 1 \mathrm{P}$ & $25.1 \pm 2.2^{*, \#}$ & $590 \pm 42 *$ \\
\hline D & $\mathrm{CS} /-$ & CS/C8-C1P & $27.4 \pm 1.3^{*, \#}$ & $609 \pm 131 *$ \\
\hline
\end{tabular}

Data are presented as mean \pm SD. Tissue sections from formalin-fixed and paraffin-embedded lungs were stained with haematoxylin-eosin. Mean linear intercept $(\mathrm{Lm})$ describes the average distance between alveolar walls in parenchyma. Internal surface area of the lungs (ISA) was performed at $25 \mathrm{~cm}$ of formalin distending pressure. $n=5$ mice per group. *: $p<0.05$, CS 7 months/vehicle 3 months versus air 7 months/ vehicle 3 months; ${ }^{\#}$ : $p<0.05$, CS 7 months/C1P 3 months versus CS 7 months/vehicle 3 months.

matrix metalloproteinase (MMP)-12 was significantly higher after 7 months in CS-exposed mice compared to air-exposed mice. Administration of C1P attenuated MMP-12 mRNA expression in CS-induced lung inflammation (fig. 3h). Additional immunohistochemistry staining of CD3 and CD20 identified lymphocytes and the appearance of lymphoid aggregates and follicles in lung tissue of mice. No lymphoid follicles were found in air-exposed mice (fig. 3i). The presence of lymphoid aggregates in CS-exposed mice was reduced by treatment with $\mathrm{C} 1 \mathrm{P}$ (fig. 3i). Our study showed an increase in the B-cell attracting chemokines CXCL13 and CXCR5, which are found in areas of inducible bronchus-associated lymphoid tissue (iBALT), in the lungs of CS-exposed mice after 7 months. In general, we were not able to detect the typical formation of iBALT in C1P treated mice (fig. 3i). Hence, C1P reduces the development of iBALT in a mouse model of chronic CS-induced lung inflammation due to attenuated mRNA expression of CXCL13 (fig. 3h).

\section{C1P reduces CS-induced NF- $\mathrm{B} B$ expression and activity in lung tissue and human AEC lines}

$\mathrm{CS}$ exposure is associated with the activation of the NF- $\mathrm{BB}$ signalling pathway in the lungs of humans and mice $[19,20]$. Thus, we next questioned whether C1P can decrease CS-induced NF- $\kappa B$ DNA binding in murine lung tissue. As shown in figure $4 \mathrm{a}$ and $\mathrm{b}$, both $\mathrm{C} 8 \mathrm{-C} 1 \mathrm{P}$ and $\mathrm{C} 16-\mathrm{C} 1 \mathrm{P}$ partially inhibited the pronounced NF- $\kappa \mathrm{B}$ DNA binding in the lung tissue induced by acute CS exposure. Furthermore, quantified PCR analysis revealed that the protective role of $\mathrm{C} 1 \mathrm{P}$ can also be linked to the reduced mRNA expression of NF- $\mathrm{BB} 1$ (fig. 4c) and NF- $\mathrm{BB}$ target genes, including MMP-9, MYD88 and TNF receptor-associated factor (TRAF) 2 expression (fig. S1).

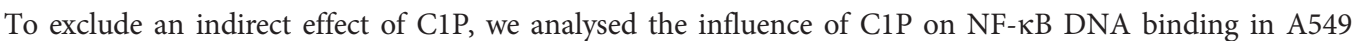
and BEAS-2B cells. For this purpose, cells were pre-incubated with the indicated concentration of $\mathrm{C} 8 \mathrm{-C} 1 \mathrm{P}$, C16-C1P or vehicle prior to stimulation with CSE (5\%) for $10 \mathrm{~min}$. Upon CSE stimulation, strong NF- $\kappa \mathrm{B}$ DNA binding was observed in BEAS-2B (fig. 4d) and A549 (fig. 4e) cells compared to vehicle-treated cells. Interestingly, both $\mathrm{C} 1 \mathrm{P}$ analogues significantly reduced CSE-induced NF- $\mathrm{B}$ DNA binding in a dose-dependent manner (fig. $4 \mathrm{f}$ and $\mathrm{g}$ ).

\section{Effect of C1P on CS-induced cytokine production and reactive oxygen species release in human} AEC lines

Based on the observation that C1P reduces CS-induced NF- $\kappa$ B DNA binding in human AECs in vitro, we then investigated whether C1P consequently modulates production of pro-inflammatory cytokines (IL-6/ IL-8) in AECs. Therefore, A549 and BEAS-2B cells were either treated with the indicated concentration of $\mathrm{C} 8-\mathrm{C} 1 \mathrm{P}, \mathrm{C} 16-\mathrm{C} 1 \mathrm{P}$ or vehicle for $1 \mathrm{~h}$ prior to CSE stimulation. Supernatants were collected after $6 \mathrm{~h}$ and cytokines were quantified. As shown in figure 5, C8-C1P and $\mathrm{C} 16-\mathrm{C} 1 \mathrm{P}$ significantly inhibited the CSE-induced production of IL-6 and IL-8. Additional reactive oxygen species (ROS) production by human AECs was determined. C1P was able to diminish CSE-induced ROS release in A549 and BEAS-2B (fig. S2).

\section{C1P attenuates CSE-induced NF-KB expression and inhibits IL-8 production in human neutrophils}

Besides AECs, neutrophils are also a major source of airway IL-8 in COPD. Therefore, we investigated the effect of C1P on CSE-induced IL-8 production in human neutrophils isolated from nonsmoking controls, ex-smoking controls and COPD patients. In line with the findings from AECs, C16-C1P and C8-C1P dose-dependently inhibited CSE-induced release of IL- 8 by neutrophils of control subjects and COPD patients with mild-to-moderate (GOLD stages I and II) and severe (GOLD stages III and IV) disease 

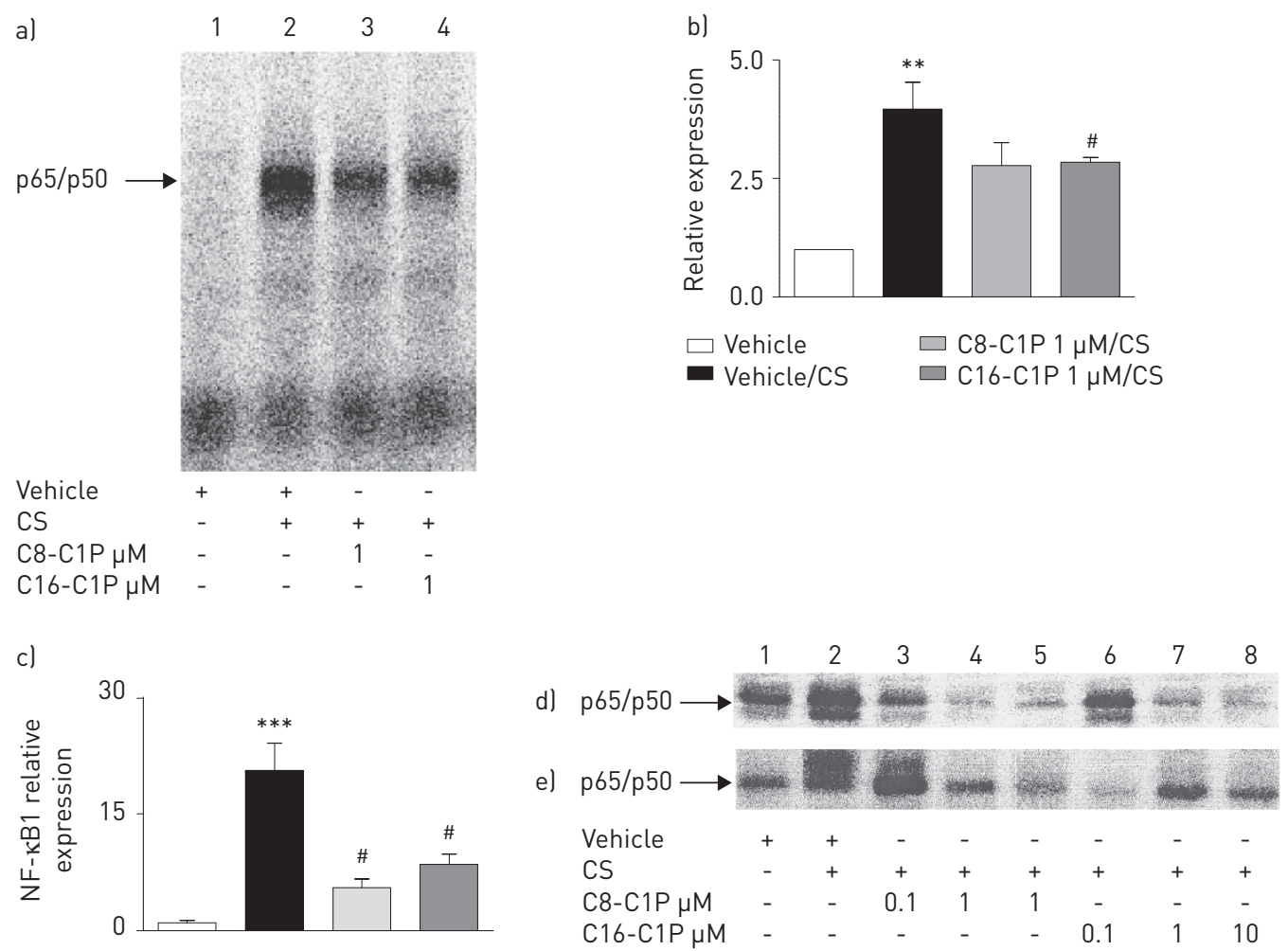

$\square$ Air 7 months/vehicle 3 months

- Smoke 7 months/vehicle 3 months

$\square$ Smoke 7 months/C16-C1P 3 months

$\square$ Smoke 7 months/C8-C1P 3 months
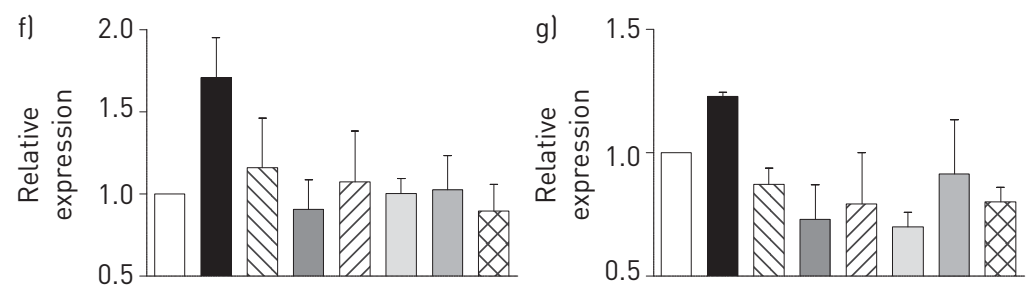

Vehicle

Vehicle/CSE

तV C8-C1P $0.1 \mu \mathrm{M} / \mathrm{CSE}$

$\square$ C8-C $1 P 1 \mu \mathrm{M} / \mathrm{CSE}$

$\square$ C8-C1P $10 \mu \mathrm{M} / \mathrm{CSE}$

$\square$ C16-C1P $0.1 \mu \mathrm{M} / \mathrm{CSE}$

$\square$ C16-C1P $1 \mu \mathrm{M} / \mathrm{CSE}$

X C16-C1P $10 \mu \mathrm{M} / \mathrm{CSE}$

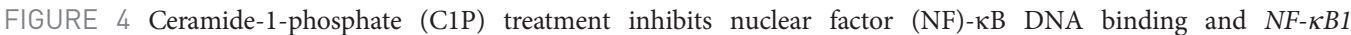
expression. a) NF- $\mathrm{B}$ DNA binding in a mouse model of acute cigarette smoke (CS)-induced lung inflammation measured by electrophoretic mobility shift assay (EMSA). b) Quantification of the bands shown in a. c) Downregulation of NF-KB1 expression in chronic CS-induced lung inflammation assessed by quantified PCR. GAPDH was used as a reference gene. Human d) BEAS-2B and e) A549 airway epithelial cell lines were treated with C16-C1P and C8-C1P for $1 \mathrm{~h}$ prior to $5 \%$ cigarette smoke extract (CSE) stimulation for $10 \mathrm{~min}$. Equal amounts of protein from total cell extracts were analysed for NF- $\mathrm{KB}$ DNA binding by EMSA. One representative EMSA out of three is shown. Quantification of the bands out of the three EMSAs is shown for f) BEAS-2B and g) A549. Data are presented as mean \pm SEM. ${ }^{* *}: \mathrm{p}<0.01$ CS 7 months/vehicle 3 months versus air 7 months/vehicle 3 months; ${ }^{* * *}$ p $<0.001$ CS 7 months/vehicle 3 months versus air 7 months/vehicle 3 months; ${ }^{*}$ : p $<0.001$ CS 7 months/C1P 3 months versus CS 7 months/vehicle 3 months.

(fig. $6 \mathrm{a}-\mathrm{d}$ ). The efficacy of C1P treatment in blocking IL-8 production was similar between the control subjects and COPD patients with mild-to-moderate (GOLD stages I and II) and severe (GOLD stages III and IV) disease. Transcriptional analysis revealed that C1P also reduced CSE-induced $N F-\kappa B 1$ level in neutrophils of COPD patients (fig. 6e).

Increased nSMase activity/expression in murine lung tissue with emphysema and CS-exposed human granulocytes and sera

It has previously been reported that CSE increases nSMase activity in AECs, resulting in an increased level of ceramide and epithelial cell apoptosis $[5,13]$. Thus, we analysed nSMase activity in the lungs of mice with CS-induced lung inflammation/emphysema, as well as in the serum of 22 COPD patients, eight 

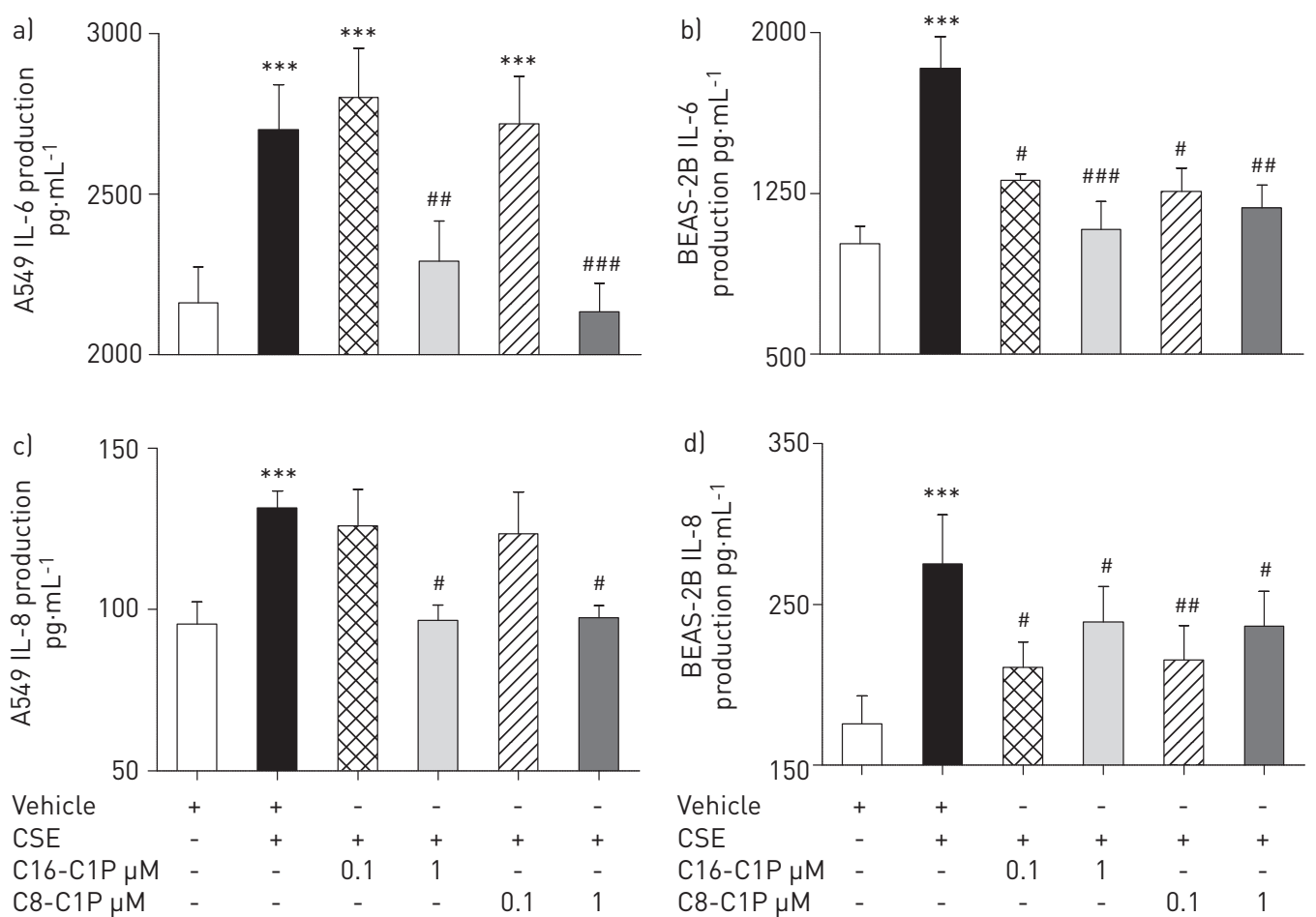

FIGURE 5 Ceramide-1-phosphate (C1P) administration prior to cigarette smoke extract (CSE) stimulation reduces interleukin (IL)-6 and IL-8 production in airway epithelial cells. C1P $0.1 \mu \mathrm{M}$ and $1 \mu \mathrm{M}$ were given to confluent a, c) A549 and b, d) BEAS-2B cells $1 \mathrm{~h}$ prior to 5\% CSE stimulation for $6 \mathrm{~h}$. The supernatant was taken and the content of a, b) IL- 6 and c, d) IL- 8 was measured by ELISA. Data are presented as mean \pm SEM. $n=10$. ${ }^{* * *}$ : $<<0.001$ vehicle/CSE versus vehicle/vehicle; ${ }^{\#}: \mathrm{p}<0.05,{ }^{\# \#}: \mathrm{p}<0.01,{ }^{\# \# \#}: \mathrm{p}<0.001 \mathrm{C} 1 \mathrm{P} / \mathrm{CSE}$ versus vehicle/CSE.

ex-smoker controls and 11 nonsmoker controls. As shown in figure 7, increased nSMase activity was detected in lung tissue of CS-exposed mice compared to air-exposed littermates (fig. 7a) and also in the sera of COPD patients compared to nonsmokers and ex-smoker controls (fig. 7b). Interestingly, there was a significant negative correlation between human serum nSMase levels and post-bronchodilator forced expiratory volume in $1 \mathrm{~s}(\mathrm{FEV} 1) \%$ predicted in COPD patients $(\mathrm{r}=-0.57 ; \mathrm{p}<0.01)$ (fig. $\mathrm{S} 3 \mathrm{a})$ and also in the entire study population $(\mathrm{r}=-0.75 ; \mathrm{p}<0.001)$ (fig. S3b).

Finally, we addressed the modulatory effect of C1P on CS-triggered nSMase activity/expression in the lung tissue of mice and human neutrophils. C8-C1P and C16-C1P significantly attenuated CS-induced nSMase activity in murine lung (fig. 7a) and nSMase2 mRNA expression in human neutrophils of COPD patients (fig. 7c).

\section{Discussion}

Sphingolipids, such as sphingosine-1-phosphate (S1P) and C1P, have been implicated in the regulation of immune response during infections, as well as in inflammatory disorders such as atherosclerosis, rheumatoid arthritis, asthma, acute respiratory distress syndrome or cystic fibrosis [9, 21-24]. It is remarkable that while the role of S1P and S1P receptor-agonists/antagonists in the pathogenesis of inflammatory disorders has been extensively studied in vivo using translational mouse models of human diseases $[9,10,25]$, the knowledge concerning the function of exogenous C1P in modulating immune responses is, at present, mostly limited to in vitro observations [26, 27]. Both pro- and anti-inflammatory behaviour of exogenous $\mathrm{C} 1 \mathrm{P}$ has been described. For instance, C1P stimulates eicosanoid (e.g. prostaglandin E2) biosynthesis, and promotes phagocytosis of neutrophils, migration of macrophages and degranulation of mast cells $[15,22,24,28]$. Conversely, C1P inhibits LPS-triggered production of pro-inflammatory cytokines such as TNF- $\alpha$, IL-6 or IL-5/IL-13 in macrophages or mast cells, as well as reducing acid SMase activity $[10,22,23,29]$.

Here, we report for the first time that both the synthetic C1P analogue C8-C1P and the natural analogue C16-C1P exert anti-inflammatory effects in a mouse model of CS-induced lung inflammation and emphysema. Intrapulmonary and systemic oral treatment attenuates CS-induced recruitment of leukocytes to the lung and production of pro-inflammatory cytokines, such as KC, MIP-2, IL-6 and IL-1 $\beta$, as well as 


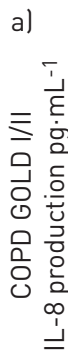

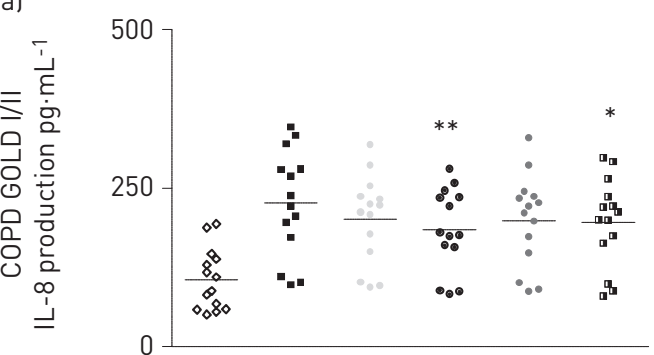

c)

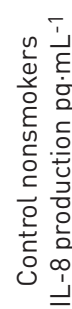

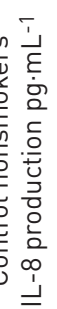

Vehicle

CSE

C16-C1P $\mu$

C8-C1P $\mu \mathrm{M}$

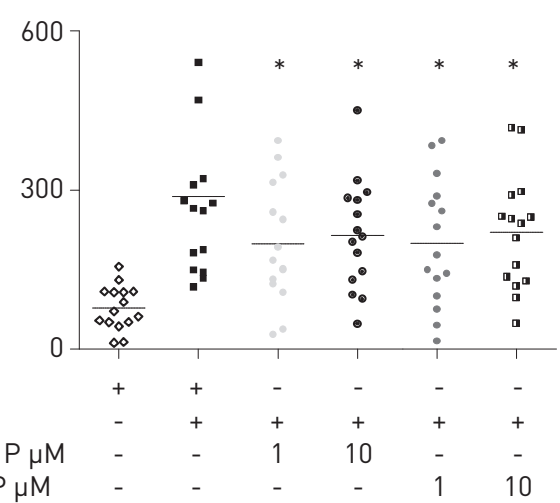

b)

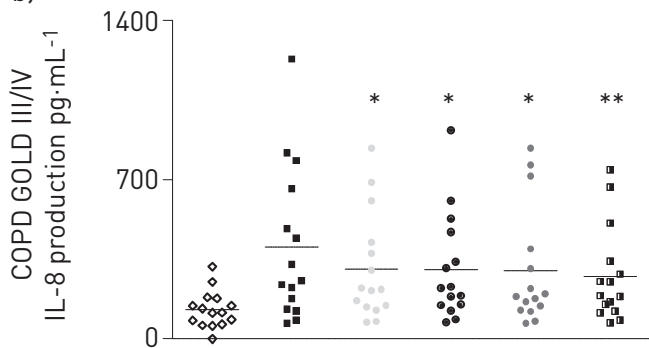

d)

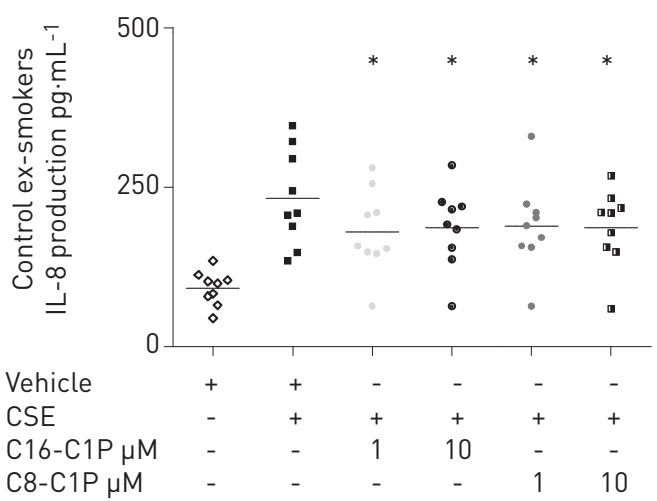

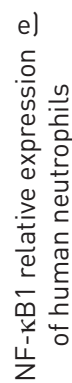

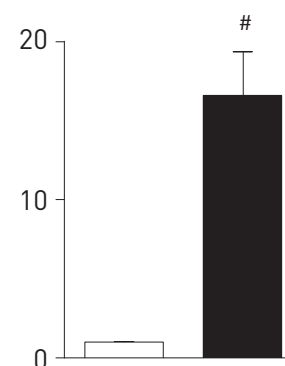

$\square$ Vehicle/medium

- Vehicle/CSE

$\square$ C16-C1P $1 \mu \mathrm{M} / \mathrm{CSE}$

$\square$ C8-C1P $1 \mu \mathrm{M} / \mathrm{CSE}$

FIGURE 6 Ceramide-1-phosphate (C1P) reduces interleukin (IL)-8 and nuclear factor (NF)- $\kappa \mathrm{B}$ expression in human neutrophils stimulated with cigarette smoke. C1P $(1 \mu \mathrm{M}$ and $10 \mu \mathrm{M})$ was administered to isolated human neutrophils $1 \mathrm{~h}$ before stimulation with $5 \%$ cigarette smoke extract (CSE). $18 \mathrm{~h}$ later IL- 8 in the supernatant was quantified by ELISA. a) Chronic obstructive pulmonary disease (COPD) Global Initiative for Chronic Obstructive Lung Disease (GOLD) I/II patients, b) COPD GOLD III/IV patients, c) control nonsmokers, and d) control ex-smokers. e) Neutrophils isolated from COPD patients were stimulated with $1 \mu \mathrm{M} \mathrm{C1P} 1 \mathrm{~h}$ prior to CSE for $3 \mathrm{~h}$ and gene expression analysis for $N F-\kappa B 1$ was performed by quantified PCR. GAPDH was used as a reference gene. Data are presented as mean \pm SEM. ${ }^{*}: \mathrm{p}<0.05$, ${ }^{* *}: \mathrm{p}<0.01 \mathrm{C} 1 \mathrm{P} /$ vehicle versus vehicle/CSE; $^{\#}: \mathrm{p}<0.05$ vehicle/CSE versus vehicle; ${ }^{\uparrow}: \mathrm{p}<0.05 \mathrm{C} 1 \mathrm{P} / \mathrm{CSE}$ versus vehicle/CSE.

development of lung emphysema. In addition, CS-induced mRNA levels of MMP-9 and MMP-12 are diminished by administration of $\mathrm{C} 1 \mathrm{P}$. Therefore, $\mathrm{C} 1 \mathrm{P}$ could prevent tissue injury and remodelling due to the reduced matrix proteolysis. Furthermore, we recognised a link between iBALT formation and emphysema development that supports the study of BRACKE et al. [30], who described an increase of CXCL13 in patients with COPD and how crucial CXCL13 is in the development of CS-induced lymphoid follicles in mice. Treatment with C1P attenuates the presence of CS-induced accumulation of lymphocytes and CXCL13, and its receptor CXCR5.

Mechanistically, we provide evidence that C1P reduces CS-induced expression and DNA binding of $\mathrm{NF}-\kappa \mathrm{B}$ in structural lung cells in vivo and in vitro. In connection with this, nSMase 2 has recently been reported to play a role in CS-triggered apoptosis of AECs [31]. Therefore, it is of significance that C1P inhibits CS-stimulated nSMase activity and expression in murine lungs and human neutrophils, respectively. We observed increased nSMase activity in the serum of patients with COPD compared to corresponding controls, which was negatively correlated to FEV1 \% pred. Overall, our findings suggest that synthetic and natural C1P analogues might be considered as new therapeutic agents for CS-induced lung inflammation and emphysema. 
$\square$ Air 7 months/vehicle 3 months

- Smoke 7 months/vehicle 3 months

$\square$ Smoke 7 months/C16-C1P 3 months

$\square$ Smoke 7 months/C8-C1P 3 months

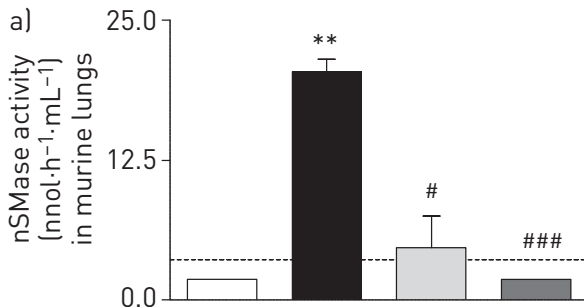

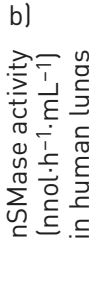
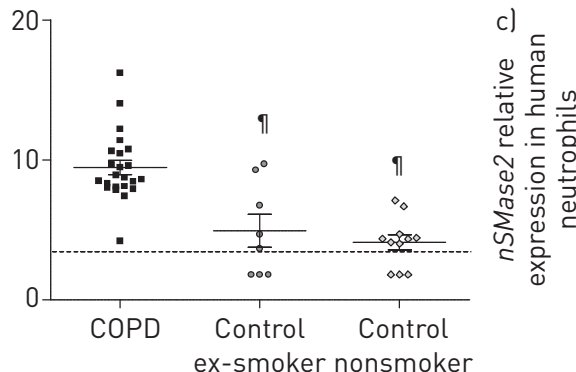

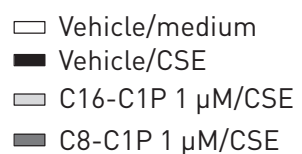

$\square$ C8-C1P $1 \mu \mathrm{M} / \mathrm{CSE}$

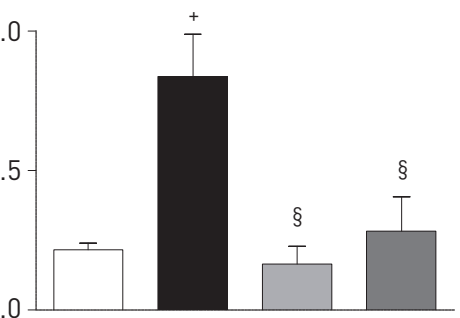

FIGURE 7 Increased neutral sphingomyelinase (nSMase) activity in murine lungs and sera of patients with chronic obstructive pulmonary disease (COPD). C57BL/6 mice were exposed to cigarette smoke (CS) for 7 months and received ceramide-1-phosphate $(\mathrm{C} 1 \mathrm{P})$ (10 $\mu \mathrm{M})$ or vehicle orally for the last 3 months. a) Lungs were isolated and nSMase activity was quantified with the SMase fluorometric assay kit. b) nSMase activity in serum from 22 patients with COPD,

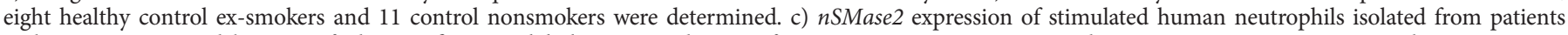
with COPD measured by quantified PCR. $\beta_{2}$-microglobulin was used as a reference gene. Data are presented as mean \pm SEM. $\mathrm{n}=5 \mathrm{mice}$ in each group. -- - -: detection limit of the nSMase fluorometric assay. ${ }^{* *}: \mathrm{p}<0.01 \mathrm{CS} 7$ months/vehicle 3 months versus air 7 months/vehicle 3 months; ${ }^{\#}$ : $<<0.01$, \#\#\#: $<0.001$ CS

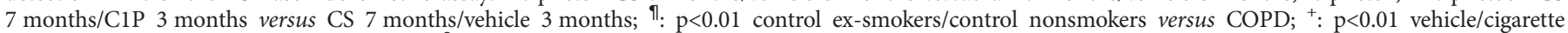
smoke extract (CSE) versus vehicle/medium; §.: $\mathrm{p}<0.01 \mathrm{C} 1 \mathrm{P} / \mathrm{CSE}$ versus vehicle/CSE.

$\mathrm{NF}-\mathrm{KB}$ is one of the key transcription factors involved in cellular responses to CS in the lungs [19, 20, 32]. Its activation leads to the induction of multiple genes associated with innate immunity, cellular inflammation and repair processes. In the present study, CS-induced NF- $\kappa B$ DNA binding and $N F-\kappa B$ expression in the lungs were reduced when mice were treated with $\mathrm{C} 8-\mathrm{C} 1 \mathrm{P}$ or $\mathrm{C} 16-\mathrm{C} 1 \mathrm{P}$, suggesting that C1P might exert its anti-inflammatory capacity by suppressing the NF- $\mathrm{KB}$ pathway. However, the decrease in NF- $\kappa$ B DNA binding might also be due to the attenuation in CS-induced lung inflammation observed upon C1P treatment. Thus, to better define the capacity of $\mathrm{C} 1 \mathrm{P}$ to modulate CS-induced NF- $\kappa \mathrm{B}$ transformation, in vitro experiments with CSE-stimulated human A549 and BEAS-2B AECs were performed. Strikingly, both C8-C1P and C16-C1P were dose-dependently able to attenuate CSE-triggered translocation of NF- $\mathrm{KB}$ into the nucleus in epithelial cell lines, implying that $\mathrm{C} 1 \mathrm{P}$, via interfering with the $\mathrm{NF}-\kappa \mathrm{B}$ pathway, regulates CS-induced lung inflammation. In this context, C1P reduces CS-triggered induction of NF- $\mathrm{KB}$ target genes expression such as Mmp9, Myd88 and Traf2 (supplementary material). Unfortunately, TNF receptor 1 and 2 were not significantly increased in our mouse models (data not shown), thus it was not possible to determine the effect of C1P on mRNA expression.

Interestingly, similar effects of $\mathrm{C} 8-\mathrm{C} 1 \mathrm{P}$ and/or C16-C1P on LPS-induced NF- $\mathrm{B}$ activation in human embryonic kidney cells and primary human peripheral blood mononuclear cells have been demonstrated [33]. However, other studies reported that high concentrations of C16-C1P (15 or $20 \mu \mathrm{M})$ stimulated NF- $\kappa \mathrm{B}$ activation in the alveolar rat macrophage cell line NR8383 [12] and murine macrophage cell line J774A.1 [15]. Nevertheless, Goldsmith et al. [14] did not observe any effect of phospho-ceramide analogue-1, a

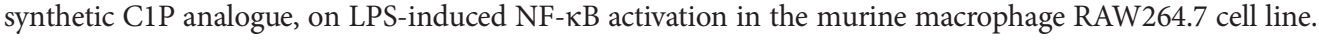

An explanation for this discrepancy might be the different C1P concentration $(1-20 \mu \mathrm{M})[12,15,33]$ and the $\mathrm{C} 1 \mathrm{P}$ analogue, as well as the different cell types used in these studies. Of note, the solvent in which $\mathrm{C} 1 \mathrm{P}$ is dispersed has been reported to be critical for its pro- or anti-inflammatory action. For instance, C1P was often dissolved in either methanol/dodecane [11] or ethanol/dodecane [34], and dodecane is known to influence the effect of C1P [29]. To avoid this, we used C16-C1P sonicated in sterile water or C8-C1P dispersed in ethanol/PBS or medium (1:2000-1:200 000 dilution).

Since NF- $\mathrm{\kappa B}$ pathway activation leads to the induction of pro-inflammatory cytokines in various cell types $[4,18,23,35]$, we investigated whether the CSE-induced production of IL- 8 and IL- 6 by A549 and BEAS-2B cells is also regulated by $\mathrm{C} 1 \mathrm{P}$. Indeed, C8-C1P and C16-C1P dose-dependently inhibited CSE-triggered production of IL-8 and IL-6 in AECs.

Furthermore, we have shown an increase of ROS level produced by A549 and BEAS-2B when they were stimulated with CSE. The reduced ROS release through C1P stimulation could prevent cellular damage or accumulation of oxidative stress.

Nevertheless, oxidative stress in the airways following CS exposure also causes activation of an endogenous membrane nSMase. CHEN et al. [35] found that peptidoglycan- or LPS-stimulated RAW264.7 macrophages 
release ceramide through the activation of nSMase, which further initiates the NF- $\mathrm{B}$ pathway [35]. Thus, the stimulation of nSMase seems to be required for CS-induced apoptosis of AECs [13, 31]. Of note, FiLosto et al. [31] found higher levels of nSMase2 in lung tissue of emphysema patients in comparison to control subjects. Thus, nSMase has recently gained attention as a new therapeutic strategy for CS-induced lung inflammation and lung injury. Strikingly, we found elevated nSMase activity in the lungs of mice chronically exposed to CS and, more importantly, significantly higher levels of nSMase in the serum of patients with COPD compared to never- and former smokers. Notably, enzyme activity was negatively correlated with airflow limitation (FEV1 \% pred), further underlining the potential role of nSMase in the pathogenesis of COPD. Moreover, treatment of mice with both $\mathrm{C1P}$ analogues decreased nSMase activity in the lungs, demonstrating an additional anti-inflammatory action of C1P. We suggest that the inhibition of nSMase by $\mathrm{C} 1 \mathrm{P}$ decreases ceramide level and consequently influences NF- $\mathrm{KB}$ signalling and the development of emphysema. However, to fully clarify whether ceramide or one of its metabolites regulates these effects, further studies investigating the total ceramide level in the context of CS-induced lung inflammation and the treatment with $\mathrm{C} 1 \mathrm{P}$ are needed. Interestingly, an inhibitory effect of C1P has previously been reported for another isoform of the enzyme, the acid SMase in murine bone marrow macrophages [11], although its activity is not modified in CS-induced lung inflammation [31]. Furthermore, it has been shown that $\mathrm{C} 1 \mathrm{P}$ can directly interact with serine palmitoyl transferase to block its activity [12]. Hence, we suggest C1P might also inhibit the nSMase isoform due to interaction with this ceramide-generating enzyme. Further analysis could reveal the level of $\mathrm{C} 1 \mathrm{P}$, ceramide, S1P, ceramide kinase, SMase and glycosylceramide synthase in the lungs and plasma of healthy controls compared to COPD patients, leading us to fully understand the complex metabolism of sphingolipids. Additionally, it would be interesting to investigate how exogenous C1P modifies the level of these lipids so that a concrete target can be found for future drug development.

It is worth mentioning that the anti-inflammatory effect of C1P on CS-induced lung inflammation is not limited to the modulation of structural cells, as both $\mathrm{C} 8-\mathrm{C} 1 \mathrm{P}$ and $\mathrm{C} 16-\mathrm{C} 1 \mathrm{P}$ also reduce CSE-triggered upregulation of nSMase and NF- $\kappa \mathrm{B}$ expression, and consequently IL-8-production, in human neutrophils. Neutrophils are known to play an essential role in the pathogenesis of COPD and, moreover, the modulation of the CXCR2/IL-8 axis has previously been implicated as a therapeutic strategy for COPD [36]. Thus, our observation that C1P inhibits CS-induced IL-8 production in AECs and neutrophils further strengthens our assumption that $\mathrm{C} 1 \mathrm{P}$ might be a new therapeutic target for COPD. The potential of C1P to dampen pro-inflammatory cytokine production has also been reported for LPS-induced TNF- $\alpha$, MIP-2, IL-6 and IL-8 in human embryonic kidney cells, human blood mononuclear cells, endothelial cells and mastocytes [27, 33, 37].

COPD is a complex obstructive pulmonary disease characterised by irreversible and progressive airflow limitation. Although the effect of $\mathrm{C} 1 \mathrm{P}$ on the progression of COPD was characterised by pulmonary inflammation, air space enlargement and parenchymal destruction, there is still need for further analysis of the respiratory function of mice to consider the clinical relevance of how C1P treatment affects respiratory mechanics.

In summary, we have demonstrated for the first time that $\mathrm{C} 1 \mathrm{P}$ analogues inhibit CS-induced lung inflammation and emphysema in mouse models of COPD. Mechanistically, we showed that C1P interferes with CS-induced activation of the NF- $\kappa \mathrm{B}$ pathway, consequently inhibiting pro-inflammatory cytokine production (such as IL-6 and IL-8) by human AECs and blood neutrophils, and also attenuating CS-induced induction of nSMase activity in the lungs and neutrophils of COPD patients. Thus, C1P analogues might hold promise as novel treatment options in COPD.

\section{Acknowledgements}

We would like to thank Barbara Schuler (Dept of Pharmaceutical Biology and Biotechnology, University Hospital Freiburg, Freiburg, Germany) for assistance in performing the electrophoretic mobility shift assays and Madelon Hossfeld (Dept of Pneumology, COPD and Asthma Research Group, University Hospital Freiburg, Freiburg, Germany) for support with the immunohistochemistry.

\section{References}

1 Global Initiative for Chronic Obstructive Lung Disease. Global strategy for the diagnosis, management, and prevention of chronic obstructive pulmonary disease. Updated 2014. www.goldcopd.com/uploads/users/files/ GOLD_Report_2014_Oct30.pdf Date last updated: 2014. Date last accessed: January 8, 2014.

2 Barnes PJ, Shapiro SD, Pauwels RA. Chronic obstructive pulmonary disease: molecular and cellular mechanisms. Eur Respir J 2003; 22: 672-688.

3 McDonough JE, Yuan R, Suzuki M, et al. Small-airway obstruction and emphysema in chronic obstructive pulmonary disease. N Engl J Med 2011; 365: 1567-1575.

4 Mukaida N, Mahe Y, Matsushima K. Cooperative interaction of nuclear factor-kappa B- and cis-regulatory enhancer binding protein-like factor binding elements in activating the interleukin- 8 gene by pro-inflammatory cytokines. J Biol Chem 1990; 265: 21128-21133. 
Petrache I, Natarajan V, Zhen L, et al. Ceramide upregulation causes pulmonary cell apoptosis and emphysema-like disease in mice. Nat Med 2005; 11: 491-498.

6 Becker KA, Riethmuller J, Luth A, et al. Acid sphingomyelinase inhibitors normalize pulmonary ceramide and inflammation in cystic fibrosis. Am J Respir Cell Mol Biol 2010; 42: 716-724.

7 Schweitzer KS, Hatoum H, Brown MB, et al. Mechanisms of lung endothelial barrier disruption induced by cigarette smoke: role of oxidative stress and ceramides. Am J Physiol Lung Cell Mol Physiol 2011; 301: L836-L846.

8 Niwa S, Urtz N, Baumruker T, et al. Ovalbumin-induced plasma interleukin-4 levels are reduced in ceramide kinase-deficient DO11.10 RAG1-/- mice. Lipids Health Dis 2010; 9: 1.

9 Idzko M, Hammad H, van Nimwegen M, et al. Local application of FTY720 to the lung abrogates experimental asthma by altering dendritic cell function. J Clin Invest 2006; 116: 2935-2944.

10 Chalfant CE, Spiegel S. Sphingosine 1-phosphate and ceramide 1-phosphate: expanding roles in cell signaling. J Cell Sci 2005; 118: 4605-4612.

11 Gomez-Munoz A, Kong JY, Salh B, et al. Ceramide-1-phosphate blocks apoptosis through inhibition of acid sphingomyelinase in macrophages. J Lipid Res 2004; 45: 99-105.

12 Granado $\mathrm{MH}$, Gangoiti P, Ouro A, et al. Ceramide 1-phosphate inhibits serine palmitoyltransferase and blocks apoptosis in alveolar macrophages. Biochim Biophys Acta 2009; 1791: 263-272.

13 Levy M, Khan E, Careaga M, et al. Neutral sphingomyelinase 2 is activated by cigarette smoke to augment ceramide-induced apoptosis in lung cell death. Am J Physiol Lung Cell Mol Physiol 2009; 297: L125-L133.

14 Goldsmith M, Avni D, Levy-Rimler G, et al. A ceramide-1-phosphate analogue, PCERA-1, simultaneously suppresses tumour necrosis factor-alpha and induces interleukin-10 production in activated macrophages. Immunology 2009; 127: 103-115.

15 Arana L, Ordonez M, Ouro A, et al. Ceramide 1-phosphate induces macrophage chemoattractant protein-1 release: involvement in ceramide 1-phosphate-stimulated cell migration. Am J Physiol Endocrinol Metab 2013; 304: E1213-E1226.

16 Lucattelli M, Cicko S, Muller T, et al. P2X7 receptor signaling in the pathogenesis of smoke-induced lung inflammation and emphysema. Am J Respir Cell Mol Biol 2011; 44: 423-429.

17 Cicko S, Lucattelli M, Muller T, et al. Purinergic receptor inhibition prevents the development of smoke-induced lung injury and emphysema. J Immunol 2010; 185: 688-697.

18 Libermann TA, Baltimore D. Activation of interleukin-6 gene expression through the NF-kappa B transcription factor. Mol Cell Biol 1990; 10: 2327-2334.

19 Vlahos R, Bozinovski S, Jones JE, et al. Differential protease, innate immunity, and NF-kappaB induction profiles during lung inflammation induced by subchronic cigarette smoke exposure in mice. Am J Physiol Lung Cell Mol Physiol 2006; 290: L931-L945.

20 Di Stefano A, Caramori G, Oates $\mathrm{T}$, et al. Increased expression of nuclear factor- $\kappa \mathrm{B}$ in bronchial biopsies from smokers and patients with COPD. Eur Respir J 2002; 20: 556-563.

21 Teichgraber V, Ulrich $\mathrm{M}$, Endlich $\mathrm{N}$, et al. Ceramide accumulation mediates inflammation, cell death and infection susceptibility in cystic fibrosis. Nat Med 2008; 14: 382-391.

22 Lamour NF, Chalfant CE. Ceramide-1-phosphate: the "missing" link in eicosanoid biosynthesis and inflammation. Mol Interv 2005; 5: 358-367.

23 Matsusaka T, Fujikawa K, Nishio Y, et al. Transcription factors NF-IL6 and NF-kappa B synergistically activate transcription of the inflammatory cytokines, interleukin 6 and interleukin 8. Proc Natl Acad Sci USA 1993; 90: 10193-10197.

24 Nixon GF. Sphingolipids in inflammation: pathological implications and potential therapeutic targets. $\mathrm{Br} J$ Pharmacol 2009; 158: 982-993.

25 Fyrst H, Saba JD. An update on sphingosine-1-phosphate and other sphingolipid mediators. Nat Chem Biol 2010; 6: 489-497.

26 Arana L, Gangoiti P, Ouro A, et al. Ceramide and ceramide 1-phosphate in health and disease. Lipids Health Dis 2010; 9: 15.

27 Gomez-Munoz A, Gangoiti P, Arana L, et al. New insights on the role of ceramide 1-phosphate in inflammation. Biochim Biophys Acta 2013; 1831: 1060-1066.

28 Granado $\mathrm{MH}$, Gangoiti P, Ouro A, et al. Ceramide 1-phosphate (C1P) promotes cell migration involvement of a specific C1P receptor. Cell Signal 2009; 21: 405-412.

29 Tauzin L, Graf C, Sun M, et al. Effects of ceramide-1-phosphate on cultured cells: dependence on dodecane in the vehicle. J Lipid Res 2007; 48: 66-76.

30 Bracke KR, Verhamme FM, Seys LJ, et al. Role of CXCL13 in cigarette smoke-induced lymphoid follicle formation and chronic obstructive pulmonary disease. Am J Respir Crit Care Med 2013; 188: 343-355.

31 Filosto S, Castillo S, Danielson A, et al. Neutral sphingomyelinase 2: a novel target in cigarette smoke-induced apoptosis and lung injury. Am J Respir Cell Mol Biol 2011; 44: 350-360.

32 Comer DM, Kidney JC, Ennis M, et al. Airway epithelial cell apoptosis and inflammation in COPD, smokers and nonsmokers. Eur Respir J 2013; 41: 1058-1067.

33 Hankins JL, Fox TE, Barth BM, et al. Exogenous ceramide-1-phosphate reduces lipopolysaccharide (LPS)-mediated cytokine expression. J Biol Chem 2011; 286: 44357-44366.

34 Pettus BJ, Bielawska A, Subramanian P, et al. Ceramide 1-phosphate is a direct activator of cytosolic phospholipase A2. J Biol Chem 2004; 279: 11320-11326.

35 Chen BC, Chang HM, Hsu MJ, et al. Peptidoglycan induces Cyclooxygenase-2 expression in macrophages by activating the neutral sphingomyelinase-ceramide pathway. J Biol Chem 2009; 284: 20562-20573.

36 Barnes PJ. New anti-inflammatory targets for chronic obstructive pulmonary disease. Nat Rev Drug Discov 2013; 12: 543-559.

37 Chiba N, Masuda A, Yoshikai Y, et al. Ceramide inhibits LPS-induced production of IL-5, IL-10, and IL-13 from mast cells. J Cell Physiol 2007; 213: 126-136. 